\title{
Mechanical Property Characterization of a Polymeric Nanocomposite Reinforced by Graphitic Nanofibers with Reactive Linkers
}

\author{
L. ROY Xu, ${ }^{1, *}$ VIKRAM BHAMIDIPATI, ${ }^{1}$ WEI-HONG ZHONG, ${ }^{2}$ \\ JIANG LI $^{2}$ AND CHARLES M. LUKEHART ${ }^{2}$ \\ ${ }^{I}$ Department of Civil and Environmental Engineering \\ ${ }^{2}$ Department of Chemistry \\ Vanderbilt Institute of Nanoscale Science and Engineering \\ Vanderbilt University, Nashville, TN 37235, USA
Edgar Lara-Curzio, Kenneth C. LiU and Michael J. Lance
Metals and Ceramics Division
Oak Ridge National Laboratory
P.O. Box 2008, Oak Ridge, TN 37831, USA

(Received October 15, 2003)

(Accepted January 26, 2004)

\begin{abstract}
Mechanical property characterization including bending, tensile, and fracture properties for a new functionalized nanofiber/epoxy composite were conducted. Results show that there was only very little increase in mechanical properties of nanocomposites although we used GCNF-ODA reactive linkers to improve the interface. The interfacial stress level of nanocomposites should be much higher than that of traditional composites because of high property mismatch between the nanoscale reinforcement and the matrix. In order to design strong and stiff nanocomposite materials, one should use aligned nanofibers with a relatively large volume or weight fraction. Also, the length of the nanofiber should be long enough and its diameter not very small in order to facilitate the interfacial load transfer mechanism.
\end{abstract}

KEY WORDS: nanocomposite materials, graphite nanofibers, epoxy matrix, ultrasonic processing, mechanical property characterization.

*Author to whom correspondence should be addressed. E-mail: 1.roy.xu@vanderbilt.edu 


\section{INTRODUCTION}

Since CARBOn nANOTUBes have extraordinary mechanical properties, they tend to $\checkmark$ be used as reinforcements in polymers and other matrices to form so-called "nanocomposite materials" [1-3]. Nanocomposites are a novel class of composite materials where one of the constituents has dimensions in the range between 1 and $100 \mathrm{~nm}$ [4]. Nanocomposite materials garner most of their material improvements from interactions at the molecular scale, influencing physical and material parameters at scales inaccessible by traditional filler materials. In Wagner et al. [5] it was reported that load transfer through a shear stress mechanism was seen at the molecular level. It has been reported that nanotubes increased the composite strength by as much as $25 \%$ [6]. However, multi-wall nanotubes (MWNTs) are limited in their applications because of weak inter-shell interactions [7]. Single wall nanotubes (SWNTs) on the other hand are quite expensive and difficult to manufacture. Alternative reinforcement materials for nanocomposites include graphitic carbon nano-fibers (GCNFs) and graphite nanoplatelets etc. [8]. GCNFs also have excellent properties and can be used as reinforcements in various kinds of matrices. They offer chemically facile sites that can be functionalized with additives thereby resulting in a strong interfacial bond with the matrix. Generally, the three main mechanisms of interfacial load transfer are micromechanical interlocking, chemical bonding, and the weak van der Waals force between the matrix and the reinforcements [9]. In order to form a nanocomposites material with excellent mechanical properties, strong chemical bonding between the reinforcement and the matrix is a necessary condition, but might not be a sufficient condition. From the length-scale argument it is known that the effective toughening may not be energetically favorable at the nano length-scale [10]. This generally necessitates a filler size greater than $100 \mathrm{~nm}$ [11]. As illustrated in Figure 1, there might be significant difference in mechanical behaviors between a continuous fiberreinforced composite (e.g., carbon fiber-reinforced composites, reinforced concrete) and a nanofiber-reinforced composite, even if both have very strong interfacial bonding. It has been proved that a continuous fiber-reinforced composite can effectively arrest the propagation of a major crack (which determines the material strength and toughness), while the short nanofiber/nanotubes might not have this kind of effect [12]. Here the length of nanofibers/nanotubes plays an important role in the toughening mechanism of nanocomposites as reported in some recent investigations $[13,14]$.

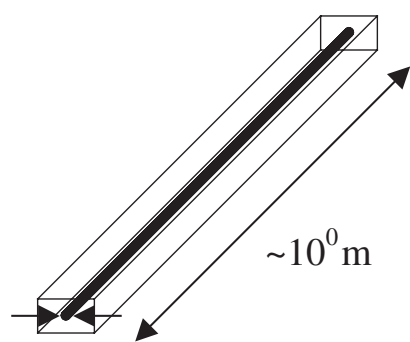

$\sim 10^{-3} \mathrm{~m}$

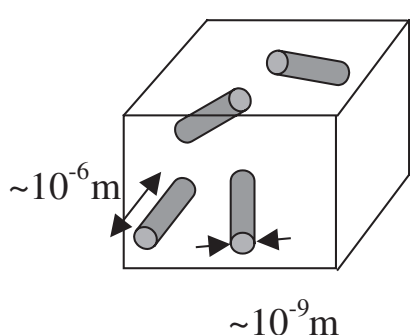

Nanocomposite (Nanoscale)

Traditional composites (Macroscale)

Figure 1. Composites materials in terms of length-scales of reinforcements. 
In this investigation, we employed GCNFs as reinforcements in polymeric matrix nanocomposites. Strong and stiff GCNFs (Young's modulus (E) $>600 \mathrm{GPa}$ ) can be prepared as crystalline graphite fibers having average diameters as small as $25 \mathrm{~nm}$ and having atomic structures such that edge carbon atom surface sites are present along the entire length of the carbon nanofiber. Chemical modification of these surface carbon sites and subsequent reaction with bifunctional linker molecules provides surface-derivatized GCNFs that can covalently bind to polymer resin molecules. By ensuring that a high number of surface sites on each GCNF form covalent bonds to polymer resin molecules, a carbon nanofiber/polymer interface of high covalent binding integrity can be achieved. This fiber/polymer covalent binding is expected to delay interfacial debonding and should enhance the mechanical properties of the resulting $\mathrm{GCNF} /$ polymer nanocomposite material. So far, it is difficult to directly measure the improved interfacial bonding between the matrix and the nanofiber. However, mechanical properties of the final nanocomposite materials can be easily measured using various kinds of standard tests for engineering materials. To achieve maximum utilization of the properties of nanofibers, uniform dispersion and good wetting of the nanofibers within the matrix must be ensured [15-17]. It has been extensively reported that dry nanofibers often agglomerate, and thereby greatly reduce their ability to bond with the matrix. All these local interfacial properties will affect the macro-level material behavior $[18,19]$. For example, it was reported that there was as much as a $10 \%$ decrease in flexural strength in nanotube/epoxy composite beams due to weakly bonded interfaces [20].

In this investigation, chemical modification of nanofiber surfaces is used to augment attractive interactions at the fiber/polymer interface. Various kinds of processing conditions were explored to ensure that nanofibers were highly dispersed within the epoxy matrix. Ultrasonic methods [21], including low-power sonication using an ultrasonic cleaner and high-power sonication using a commercial sonifier, were investigated as a means to disperse nanofibers. The dispersion quality of the nanocomposite is assessed through various kinds of mechanical tests and Transmission Electron Microscopy (TEM) analysis.

\section{EXPERIMENTAL DETAILS}

\section{Material Synthesis and Processing}

GCNFs having a herringbone atomic structure were prepared and surface derivatized by covalently attaching 3,4'-oxydianiline (ODA) linker molecules to surface carbon sites at a number density of ca. 1 ODA group/300 total bulk $\mathrm{C}$ atoms. These GCNF-ODA nanofibers contain a pendant primary amino functional group. Reaction of these derivatized nanofibers with butyl glycidyl ether (an epoxy resin monomer) under ultrasonication gives reactive carbon nanofibers (r-GCNF-ODA) of small average length in which the surface linker molecules have been chemically terminated with epoxy resin-like functional groups. Herringbone-type carbon nanofibers were grown by the interaction of a carbon source gas with mixed-metal powder growth catalyst, following a modified literature procedure [22]. Detailed procedures on synthesis of herringbone GCNFs and GCNF-ODA are described in [23]. As-prepared herringbone GCNF and surfacederivatized GCNF-ODA nanofibers have dimensions of $50-200 \mathrm{~nm}$ in diameter and 5-10 microns in length. 
The derivatized GCNF-ODA nanofibers were used as reinforcement additives to form nanocomposite materials. Commercial bisphenol A type epoxy resins such as Epon ${ }^{\circledR} 826$ and Epon $^{\circledR} 828$ from Miller-Stepheson Chemical Company Inc. were used as matrix materials (100 parts in weight), and borontrifluoride-monoethylamine $\left(\mathrm{BF}_{3}\right.$-MEA) (Aldrich Chemical Company) was used as the curing agent, (2.75 parts in weight). Blends of epoxy, curing agent, and nanofibers were mixed at a temperature of $90^{\circ} \mathrm{C}$, sonicated at controlled power levels and duration, filtered to remove any residual large agglomerated particles, and cast into a standard mold. Air bubbles were eliminated by placing the composite samples in a vacuum oven and then cured at $120^{\circ} \mathrm{C}$ for one hour and then $170^{\circ} \mathrm{C}$ for two hours, followed by cooling at the natural cooling rate of the oven. Two TEM micrographs of the r-GCNF-ODA nanofibers in epoxy are shown in Figure 2.

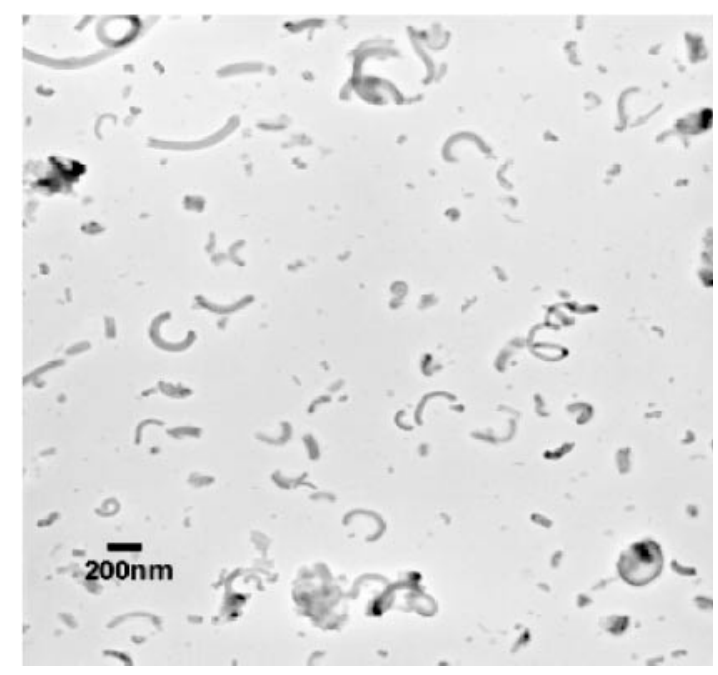

(a)

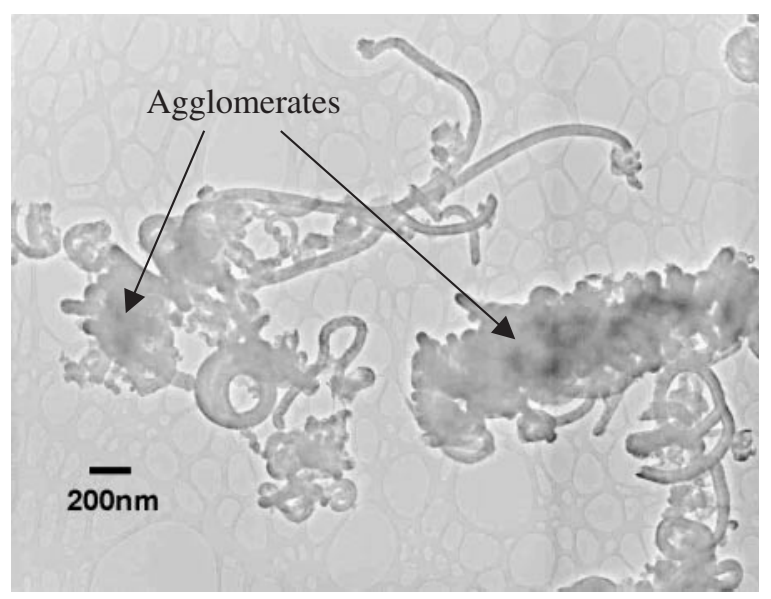

(b)

Figure 2. (a) TEM image of r-GCNF-ODA nanofibers as dispersed in GCNF/epoxy nanocomposite and (b) TEM image of agglomeration and curviness of nanofibers. Both images were from composites. 


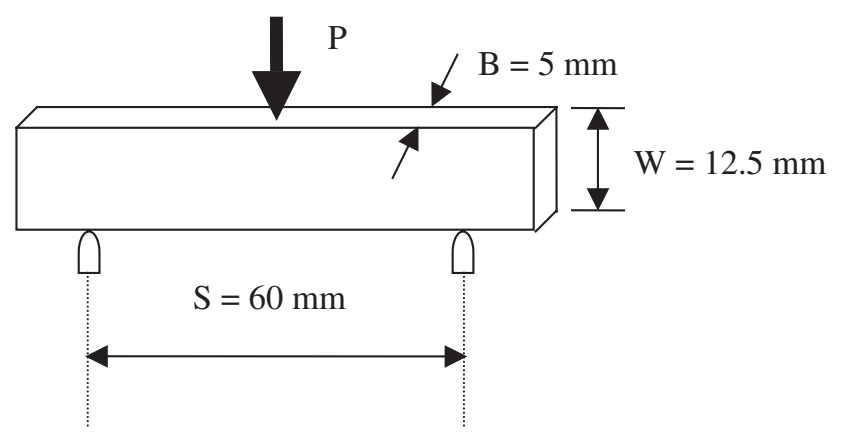

(a)

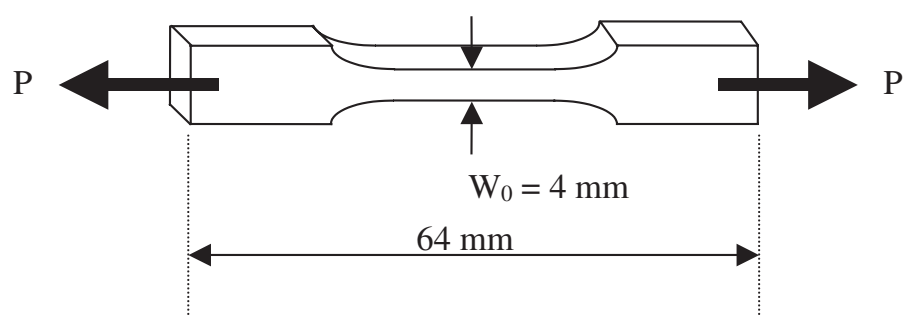

(b)

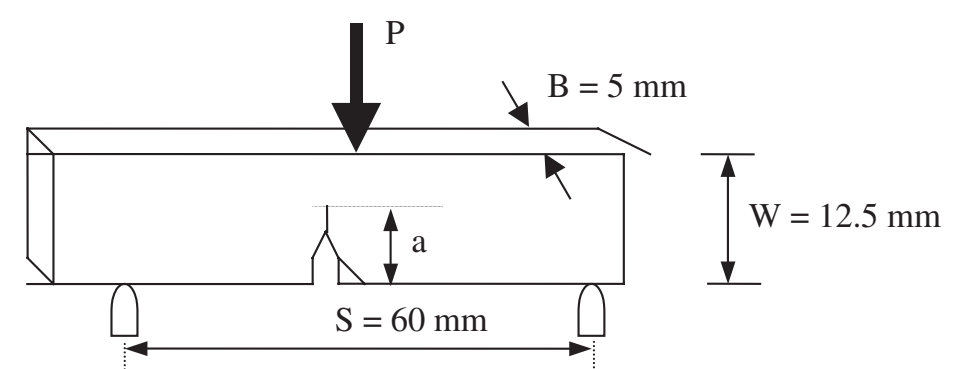

(c)

Figure 3. Experiment configurations for (a) three-point bend tests, (b) dog-bone tension tests, and (c) SENB fracture toughness tests.

In Figure 2(a), for a sonicated nanocomposite sample, uniform dispersion of nanofibers inside the epoxy resin was observed. In Figure 2(b), severe agglomeration of nanofibers was also observed when there was no sonication. In both figures, a certain degree of curviness of the nanofibers can be seen. The influence of nanofiber curviness and agglomeration on the composite mechanical properties will be investigated later. Dogbone and rectangular specimens of pure epoxy and of the final r-GCNF-ODA/epoxy nanocomposite material are illustrated in Figure 3. For some of the bending specimens, a small amount of diluent was added for good dispersion.

\section{Instruments and Testing Methods}

The nanofiber composites in this investigation contain randomly distributed nanofibers so their macro-scale mechanical properties are effectively isotropic. Also, since the nanofiber dimension and volume are quite small, the nanocomposites can be approximated as homogenous materials. Hence, we mainly use test standards for 
polymeric materials to evaluate the mechanical properties of nanocomposite materials. Because no strain rate dependence on the mechanical properties was seen in previous nanocomposite materials [24], we mainly focus on the quasi-static mechanical properties. As shown in Figure 3, three-point-bending tests, dog-bone tensile tests, and single edge notch fracture tests were conducted to characterize mechanical properties of the nanocomposites. Bending tests were conducted according to ASTM D790-00 "Standard Test Methods for Flexural Properties of Un-reinforced and Reinforced Plastics and Electrical Insulating Materials" on an MTS 810 testing machine. The loading rate was $1.0 \mathrm{~mm} / \mathrm{min}$. The span between two supports in a three-point-bending fixture was $60 \mathrm{~mm}$ as shown in Figure 3(a). About 4-6 bending specimens in each group and 19 groups in all were tested for different processing conditions and fiber contents. It should be noted that the bending strain of each specimen was not measured by direct means. Instead it was inferred from the crosshead displacement using classical beam theory. The flexural modulus data were calculated up to a maximum strain of $3 \%$ since some specimens tended to exhibit a non-linear behavior after this strain value. For dog-bone specimens (thickness ranges from $3-5 \mathrm{~mm}$ ) as shown in Figure 3(b), tensile tests were conducted on an INSTRON 5500 machine according to ASTM D638-01, "Standard Test Method for Tensile Properties of Plastics," (crosshead speed was $1.0 \mathrm{~mm} / \mathrm{min}$ ). The tensile strain was directly measured using an extensometer with a gauge length of $10.2 \mathrm{~mm}$. The fracture toughness tests were carried out according to ASTM D5045, "Standard Test Methods for Plane-Strain Fracture Toughness and Strain Energy Release Rate of Plastic Materials." Six groups with differing processing conditions and fiber contents were tested on an MTS 810 machine. A 5-mm machined notch was further cut with a razor blade to get a sharp crack with a crack tip radius of the order of tens of microns as shown in Figure 3(c).

\section{RESULTS AND DISCUSSION}

\section{Bending Experiments}

Nanocomposites with $0.07-10.0 \mathrm{wt} \%$ nanofibers and the epoxy resin were prepared for bending tests. The flexure failure of nanocomposite specimens was rather brittle compared to pure epoxy specimens. This might be due to some agglomeration of the nanofibers, since it cannot be guaranteed there is no agglomeration everywhere even when using a sonication technique. All bending results are summarized in Table 1 and illustrated in Figures 4-6. During bending experiments for some specimens, large central deflection was recorded so we plotted the nominal bending stress and strain curves to assess for the validity of the bending data. These nominal values are based on classical beam theory assuming small deformation. It is very important to examine the nominal bending stress and strain, especially since they are not directly measured during experiments, and should exhibit linear relations. However, we find that when the nominal bending strain exceeded 3.0-4.0\%, nonlinear nominal bending stress and strain relations were observed. In Table 1, we listed these nominal strain values to check whether their relevant nominal bending strengths are valid or not. For example, for group B44C samples, their nominal bending strains were as high as $5.1 \%$. Although we measured high nominal bending strengths for these samples, they were not valid measurement data. We notice that for these specimens with higher nominal bending strengths, their nominal bending strains were also quite high. 
Table 1. Data summary of three-point bending tests.

\begin{tabular}{|c|c|c|c|c|c|}
\hline \multirow{2}{*}{$\begin{array}{l}\text { Epoxy/ } \\
\text { Composite } \\
\text { Group Code }\end{array}$} & \multirow[b]{2}{*}{ Description } & \multirow[b]{2}{*}{$\begin{array}{l}\text { No. of } \\
\text { Specimens }\end{array}$} & \multicolumn{3}{|c|}{3 Point Bending Test Data } \\
\hline & & & $\begin{array}{l}\text { Failure } \\
\text { Strain \% }\end{array}$ & $\begin{array}{l}\text { Strength } \\
\text { (MPa) }\end{array}$ & $\begin{array}{c}E \\
(\mathrm{GPa})\end{array}$ \\
\hline B22C & $\begin{array}{l}\text { Epon }{ }^{\circledR} 828 \text { resin, } 0.3 \text { wt } \% \text { fibers, } \\
\text { as derivatized }\end{array}$ & 5 & 3.59 & $111.7 \pm 14.4$ & 3.169 \\
\hline $\mathrm{B} 23 \mathrm{C}$ & $\begin{array}{l}\text { Epon }{ }^{\circledR} 828 \text { resin, } 2.0 \text { wt } \% \text { fibers, } \\
\text { as derivatized }\end{array}$ & 4 & 2.24 & $72.4 \pm 12.6$ & 3.196 \\
\hline B24C & $\begin{array}{l}\text { Epon }{ }^{\circledR} 828 \text { resin, } 0.3 \text { wt } \% \text { fibers, } \\
\text { cut and reacted with diluents }\end{array}$ & 4 & 3.04 & $96.9 \pm 20.6$ & 3.145 \\
\hline B25C & $\begin{array}{l}\text { Epon }^{\circledR} 828 \text { resin, } 2.0 \text { wt } \% \text { fibers, } \\
\text { cut and reacted with diluents }\end{array}$ & 5 & 2.40 & $74.4 \pm 4.1$ & 3.154 \\
\hline B31E & Epon $^{\circledR} 826$ resin & 4 & 3.73 & $108.9 \pm 45.9$ & 3.054 \\
\hline $\mathrm{B} 32 \mathrm{C}$ & Epon $^{\circledR} 826$ resin, 0.3 wt $\%$ fibers & 5 & 2.82 & $84.8+23.2$ & 3.076 \\
\hline B33C & Epon $^{\circledR} 826$ resin, 2.0 wt\% fibers & 4 & 2.24 & $68.4 \pm 4.5$ & 3.116 \\
\hline B34C & Epon $^{\circledR} 826$ resin, 5.0 wt\% fibers & 5 & 3.62 & $107.89+38.4$ & 3.072 \\
\hline B35C & Epon ${ }^{\circledR} 826$ resin, 10.0 wt\% fibers & 5 & 2.70 & $84.9 \pm 24.1$ & 3.220 \\
\hline B36C & $\begin{array}{l}\text { Epon }^{\circledR} 826 \text { resin, } 0.5 \text { wt } \% \text { fibers, } \\
\text { cut and reacted with diluent, no drying }\end{array}$ & 5 & 3.93 & $111.9 \pm 18.1$ & 2.947 \\
\hline B44C & $\begin{array}{l}\text { Epon }{ }^{\circledR} 828 \text { resin, } 0.3 \text { wt } \% \text { fibers blend } \\
\text { reacted with } 3.6 \text { wt\% diluent }\end{array}$ & 4 & 5.1 & $139.6 \pm 4.05$ & 3.070 \\
\hline B45C & $\begin{array}{l}\text { Epon }^{\circledR} 828 \text { resin, } 2.6 \text { wt } \% \text { fibers blend } \\
\text { reacted with } 20 \text { wt\% diluent }\end{array}$ & 3 & 8.3 & No Break & 0.747 \\
\hline B46E & Epon ${ }^{\circledR} 828$ resin, 3.6 wt\% diluent & 6 & 3.46 & $94.09 \pm 10.79$ & 2.829 \\
\hline B47E & Epon ${ }^{\circledR} 828$ resin, 20 wt $\%$ diluent & 5 & 7.46 & $106.85 \pm 3.11$ & 2.410 \\
\hline B48C & $\begin{array}{l}\text { Epon }{ }^{\circledR} 828 \text { resin, } 1.3 \text { wt\% almost } \\
\text { dry fibers blend }\end{array}$ & 6 & 4.18 & $123.82 \pm 11.06$ & 3.153 \\
\hline B49C & $\begin{array}{l}\text { Epon }^{\circledR} 828 \text { resin, } 1.15 \text { wt\% almost } \\
\text { dry fibers blend }\end{array}$ & 6 & 2.56 & $80.13 \pm 5.69$ & 3.215 \\
\hline B51C & $\begin{array}{l}\text { Epon }^{\circledR} 828 \text { resin, } 0.07 \text { wt } \% \text { fibers blend } \\
\text { reacted with } 3.6 \text { wt\% diluent }\end{array}$ & 6 & 2.23 & $69.24 \pm 13.61$ & 3.211 \\
\hline B52C & $\begin{array}{l}\text { Epon }^{\circledR} 828 \text { resin, } 0.28 \text { wt } \% \text { fibers blend } \\
\text { reacted with } 3.6 \text { wt } \% \text { diluent }\end{array}$ & 6 & 4.69 & $125.3 \pm 12.25$ & 3.099 \\
\hline B53C & $\begin{array}{l}\text { Epon }^{\circledR} 828 \text { resin, } 1.48 \text { wt\% fibers blend } \\
\text { reacted with } 3.6 \text { wt\% diluent }\end{array}$ & 6 & 4.44 & $122.37 \pm 13.69$ & 3.083 \\
\hline
\end{tabular}

We can see from Figure 4 that the maximum bending strength is from the group with $0.3 \%$ nanofiber content and diluent compared to pure epoxy samples (shadowed samples). We also notice that for some nanocomposite specimens, there is a considerable decrease in bending strengths. Overall, we cannot conclude that nanofibers increase the bending strength of nanocomposites. There is a slight increase in bending moduli of various groups of nanocomposites as seen from Figure 5 when no diluent was used. Obviously, addition of diluent has a significant effect on the stiffness and strength of nanocomposites. It is interesting to note that there is only a moderate increase in stiffness even when the fiber content is increased to as much as $10 \mathrm{wt} \%$. In order to investigate the influence of nanofiber contents on the bending strength, a series of specimens with the same processing condition but different nanofiber weight percents were synthesized and tested. Their bending strengths are plotted as a function of the nanofiber content in Figure 6. We can see that there is no clear trend in bending strength increase of nanocomposites with the increasing amounts of fiber contents. The failure mechanism of these bending specimens is discussed in the Section "Failure Feature and Design Consideration of Nanocomposites." 


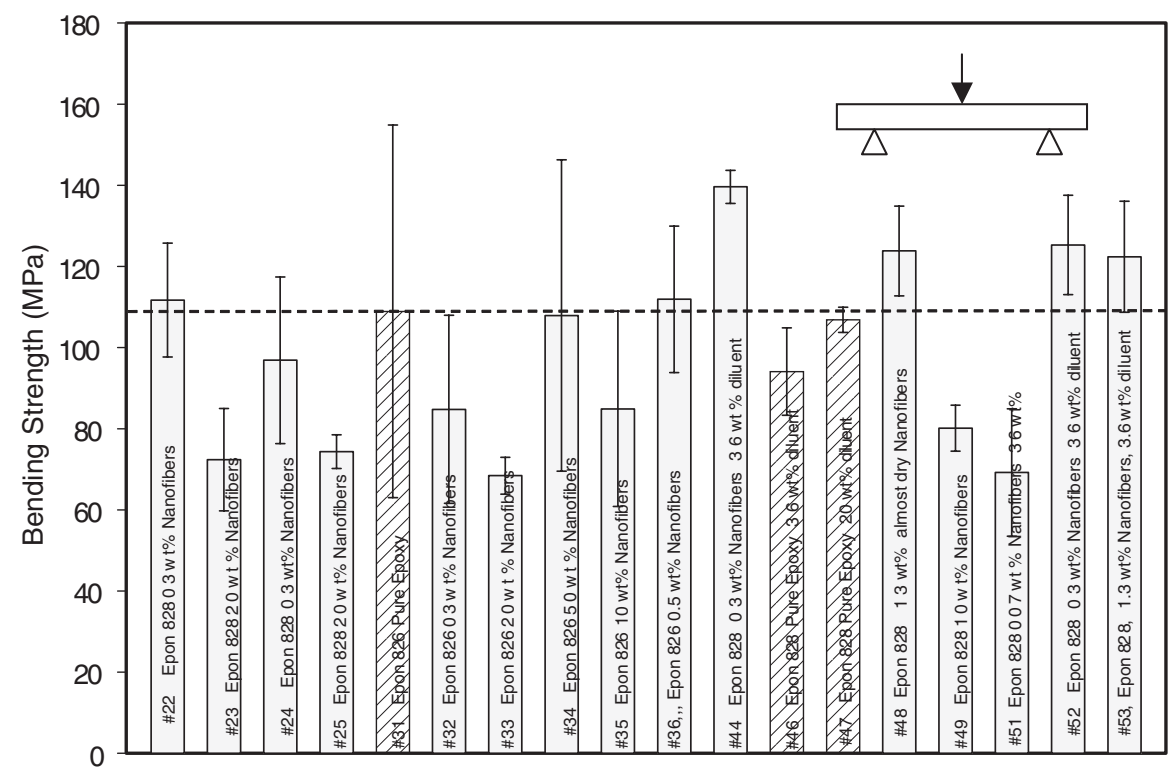

Figure 4. Summary of strength data from bending tests.

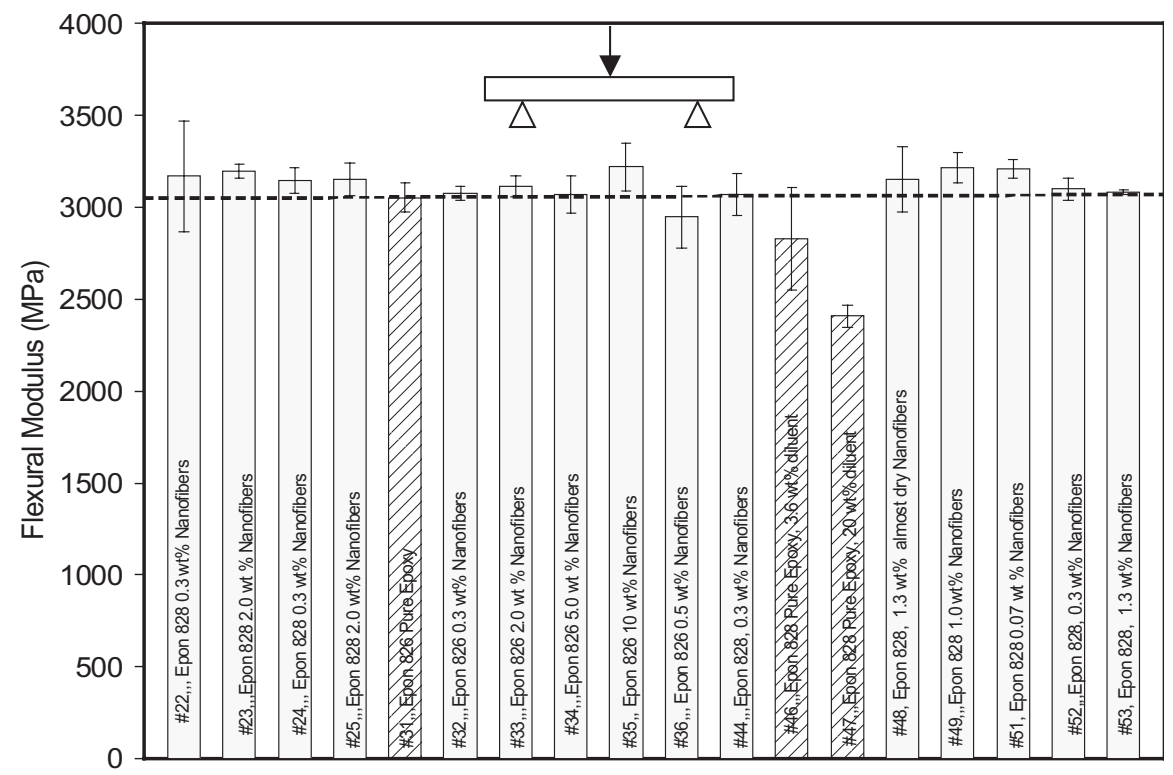

Figure 5. Summary of Young's modulus data from bending tests.

\section{Tension Experiments}

To investigate the effect of different sonication conditions such as power levels and durations on the mechanical properties of GCNF nanocomposites, tensile specimens of pure epoxy Epon ${ }^{\circledR} 828$ (non-diluted) and a series of nanocomposite specimens with 


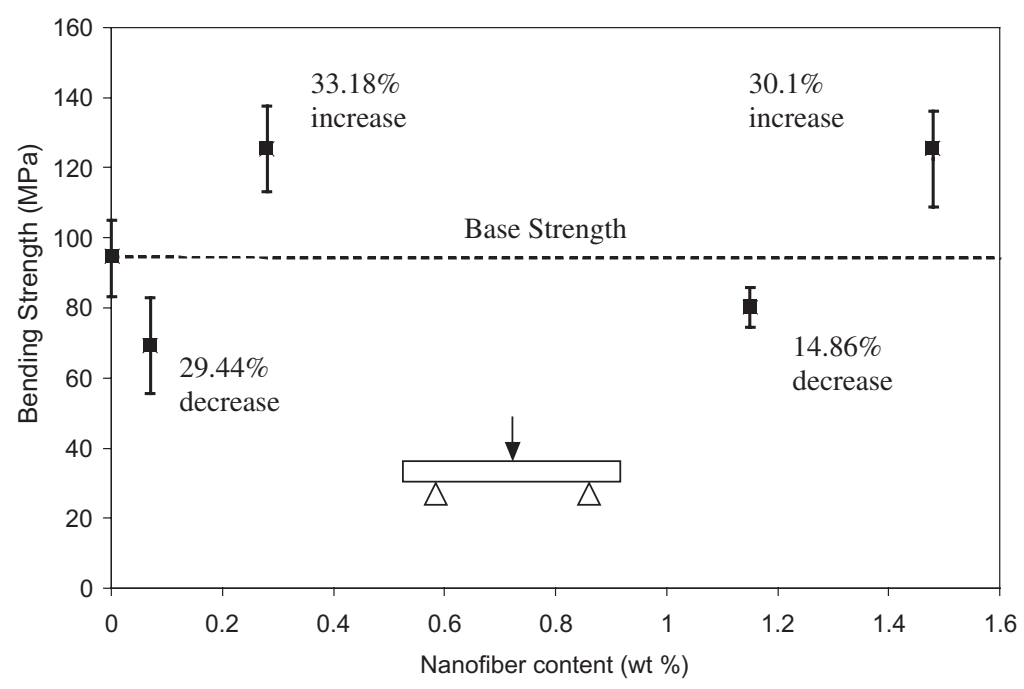

Figure 6. Bending strength as a function of fiber contents.

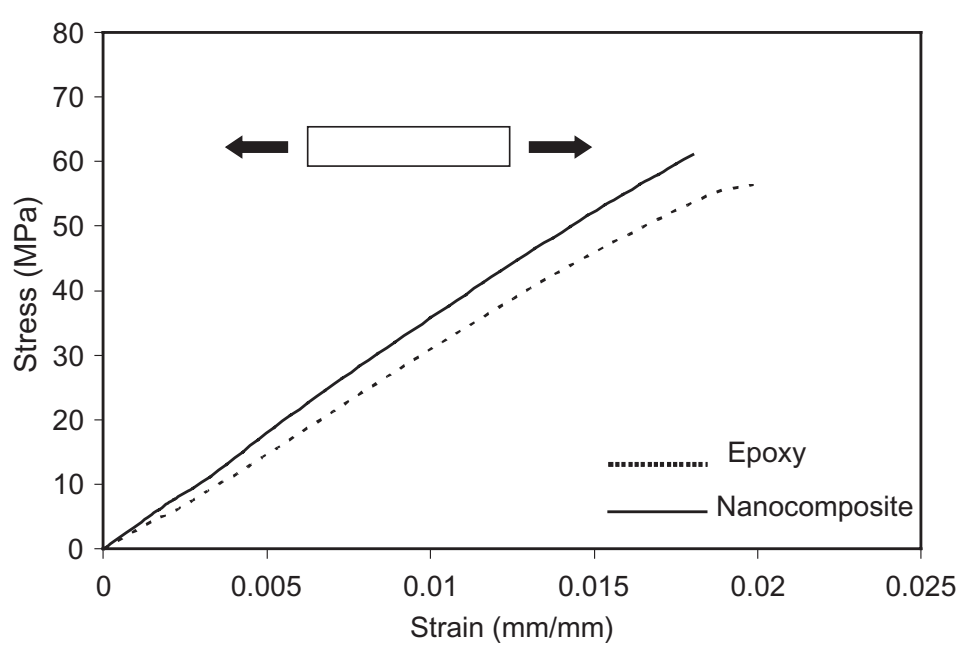

Figure 7. Tensile stress-strain curve comparison for a pure epoxy specimen and a nanocomposite specimen (0.3wt\% of nanofibers).

$0.3-2.0 \mathrm{wt} \%$ nanofiber loading were prepared. Unlike bending specimens, tensile stress and strain data were directly determined during the tensile tests. A typical tensile stressstrain curve comparison for a pure epoxy specimen and a nanocomposite specimen is shown in Figure 7. The nanofiber content for that nanocomposite specimen was $0.3 \mathrm{wt} \%$. We can see that there is a slight increase in Young's modulus and tensile strength with the addition of GCNFs. Also, there is a small increase in tensile strength of the nanocomposite specimen. However, the final failure strain of the nanocomposite specimen is lower than that of the pure epoxy specimen. Similar experiments [25] showed that while there was a slight increase in stiffness and strength of nanofiber/PEEK composites, there was a continuous decrease of the failure strain with increasing concentrations of nanofibers. 
Table 2. Data summary of tension tests.

\begin{tabular}{|c|c|c|c|c|c|}
\hline \multirow[b]{2}{*}{$\begin{array}{l}\text { Epoxy/ } \\
\text { Composite } \\
\text { Group Code }\end{array}$} & \multirow[b]{2}{*}{ Description } & \multirow[b]{2}{*}{$\begin{array}{l}\text { No. of } \\
\text { Specimens }\end{array}$} & \multicolumn{3}{|c|}{ Tension Test Data } \\
\hline & & & $\begin{array}{l}\text { Failure } \\
\text { Strain } \\
(\mathrm{mm} / \mathrm{mm})\end{array}$ & $\begin{array}{l}\text { Strength } \\
\text { (MPa) }\end{array}$ & $\begin{array}{c}E \\
(\mathrm{GPa})\end{array}$ \\
\hline T2E & Epon $^{\circledR} 828$ resin & 2 & $2.05 \%$ & $61.93 \pm 9.46$ & 3.092 \\
\hline T4C & $\begin{array}{l}\text { Epon }^{\circledR} 828 \text { resin, } 0.3 \text { wt } \% \\
\text { fibers (no linker) }\end{array}$ & 6 & $1.96 \%$ & $59.0 \pm 39.23$ & 3.124 \\
\hline T5C & $\begin{array}{c}\text { Epon }^{\circledR} 828 \text { resin, } 0.3 \text { wt } \% \text { fibers } \\
\text { (10\% Amplitude sonication) }\end{array}$ & 5 & $1.72 \%$ & $49.45 \pm 8.22$ & 2.951 \\
\hline T6C & $\begin{array}{l}\text { Epon }^{\circledR} 828 \text { resin, } 0.3 \text { wt } \% \text { fibers } \\
\text { (no sonication) }\end{array}$ & 5 & $1.83 \%$ & $54.06 \pm 10.61$ & 3.066 \\
\hline T7C & $\begin{array}{c}\text { Epon }^{\circledR} 828 \text { resin, } 0.3 \text { wt } \% \text { fibers } \\
\text { (30\% Amplitude sonication) }\end{array}$ & 6 & $1.61 \%$ & $45.69 \pm 16.26$ & 2.994 \\
\hline T8C & $\begin{array}{c}\text { Epon }^{\circledR} 828 \text { resin, } 0.3 \text { wt } \% \text { fibers } \\
\text { (50\% Amplitude sonication) }\end{array}$ & 5 & $2.41 \%$ & $60.63 \pm 7.07$ & 2.972 \\
\hline T9C & $\begin{array}{l}\text { Epon }^{\circledR} 828 \text { resin, } 0.3 \text { wt } \% \text { fibers } \\
\text { (Low energy sonication) }\end{array}$ & 4 & $2.8 \%$ & $71.32 \pm 17.95$ & 2.982 \\
\hline T10C & $\begin{array}{l}\text { Epon }^{\circledR} 828 \text { resin, } 0.3 \text { wt } \% \\
\text { fibers* }\end{array}$ & 5 & $2.63 \%$ & $53.67 \pm 11.01$ & 2.675 \\
\hline T11C & $\begin{array}{l}\text { Epon }^{\circledR} 828 \text { resin, } 0.3 \text { wt } \% \\
\text { fibers (EDM, Low Energy) }\end{array}$ & 5 & $3.04 \%$ & $56.69 \pm 13.40$ & 2.115 \\
\hline $\mathrm{T} 12 \mathrm{C}$ & $\begin{array}{l}\text { Epon }^{\circledR} 828 \text { resin, } 0.3 \text { wt } \% \\
\text { fibers, cut first }\end{array}$ & 4 & $3.42 \%$ & $57.24 \pm 8.06$ & 2.180 \\
\hline $\mathrm{T} 13 \mathrm{C}$ & $\begin{array}{l}\text { Epon }^{\circledR} 828 \text { resin, } 0.3 \text { wt } \% \\
\text { fibers ( } 10 \% \text { Amplitude sonication) }\end{array}$ & 6 & $2.09 \%$ & $56.94 \pm 8.99$ & 2.979 \\
\hline T14C & $\begin{array}{l}\text { Epon }^{\circledR} 828 \text { resin, } 0.3 \text { wt } \% \\
\text { fibers (30\% Amplitude sonication) }\end{array}$ & 6 & $2.06 \%$ & $63.06 \pm 10.27$ & 3.949 \\
\hline T16C & $\begin{array}{l}\text { Epon }^{\circledR} 828 \text { resin, } 0.3 w t \% \\
\text { fibers (no sonication) }\end{array}$ & 5 & $3.23 \%$ & $59.64 \pm 10.65$ & 2.0876 \\
\hline T18C & $\begin{array}{l}\text { Epon }^{\circledR} 828 \text { resin, } 0.3 \text { wt } \% \\
\quad \text { fibers, fiber cut, low sonication }\end{array}$ & 4 & $2.66 \%$ & $65.46 \pm 12.77$ & 3.0311 \\
\hline T19C & $\begin{array}{l}\text { Epon }^{\circledR} 828 \text { resin, } 2.0 \text { wt } \% \\
\quad \text { fibers, fiber cut, low sonication }\end{array}$ & 3 & $2.21 \%$ & $57.37 \pm 13.75$ & 2.6293 \\
\hline
\end{tabular}

All the tensile results are summarized in Table 2 and Figures 8 and 9 and the baseline epoxy properties are highlighted. The nanocomposite specimens showed no increase in ultimate tensile strengths for those specimens processed under sonication for 20-min duration at 15 watts and 50 watts (high power). By reducing the duration of sonication from 20 to $5 \mathrm{~min}$, nanofibers appear to be well dispersed without incurring apparent damage to the epoxy matrix, and thus, the tensile strengths are slightly increased. These results show that more vigorous sonication does not improve the mechanical properties of nanocomposites and even leads to possible structural damage or degradation of the epoxy matrix [23]. Indeed, our results show that the maximum strength of the nanocomposite is obtained for the low-power sonication processing condition. This result is consistent with those obtained from the bending tests of these materials. Figure 9 presents the Young's modulus comparison for various specimen groups with different processing conditions. Unlike the stiffness in bending, there is a considerable variation of the stiffness in tension. Overall, addition of nanofibers of $0.3-2.0 \mathrm{wt} \%$ does not increase the stiffness of nanocomposites. 


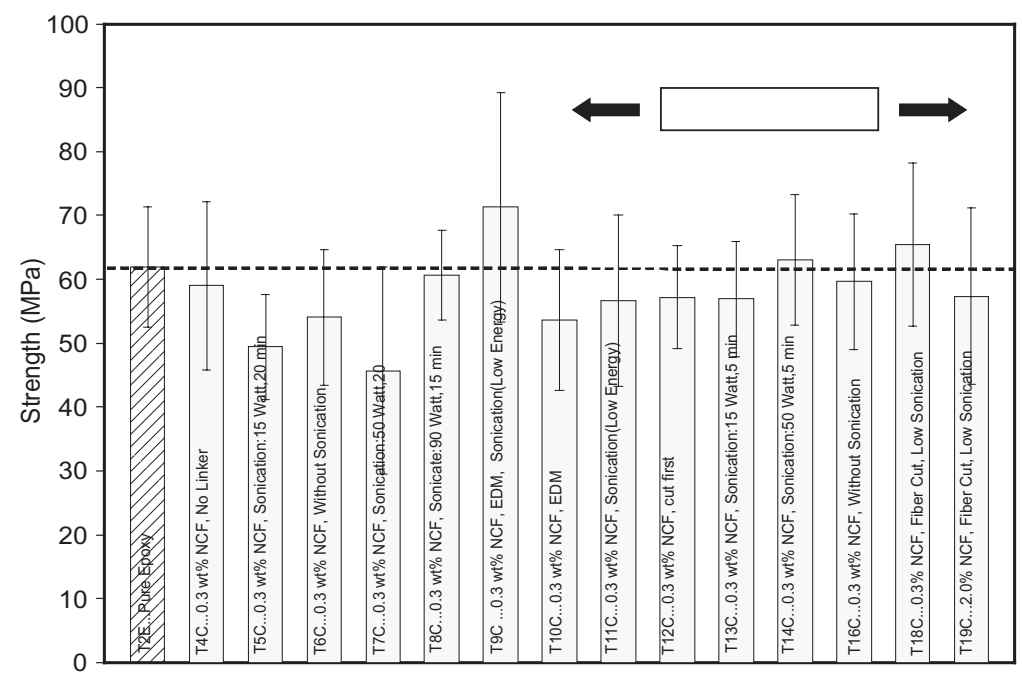

Figure 8. Tensile strengths of the pure epoxy and nanocomposite specimens with different processing conditions.

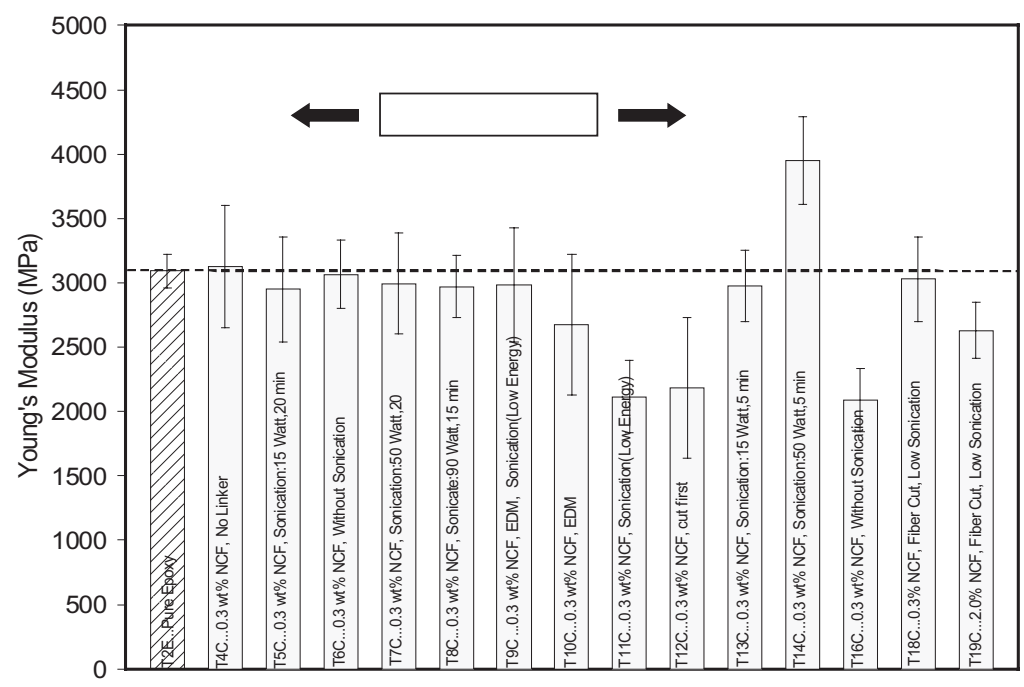

Figure 9. Young's moduli in tension of the pure epoxy and nanocomposite specimens with different processing conditions.

\section{Fracture Experiments}

Single Edge Notch Bending (SENB) tests were used to evaluate the mode-I fracture toughness of nanocomposites. The ASTM standard recommends the following specimen dimension check to ensure validity of the plane-strain fracture toughness for SENB tests:

$$
B, a,(W-a)>2.5\left(\frac{K_{\mathrm{IC}}}{\sigma_{\mathrm{Y}}}\right)^{2}
$$


where $B$ is the specimen thickness, $a$ is the initial crack length and $W$ is the specimen width as shown in Figure 3(c). For a fracture toughness $K_{\mathrm{IC}}$ of $1.5 \mathrm{MPa}(\mathrm{m})^{1 / 2}$ and a nominal yield strength $\sigma_{\mathrm{Y}}$ of $50 \mathrm{MPa}$ for pure epoxy used in this investigation, we have a critical dimension given by the above equation as $2.25 \mathrm{~mm}$. All the specimen dimensions in Equation (1) exceed this value thus ensuring validity of Linear Elastic Fracture Mechanics. From the ASTM standard D 5045 the value of $K_{\mathrm{IC}}$ is given as follows:

$$
\begin{aligned}
K_{\mathrm{IC}} & =\left(\frac{P_{Q} S}{B W^{3 / 2}}\right) f(x) \quad 0<x=a / W<1 \\
f(x) & =\frac{3}{2} \sqrt{x} \frac{\left[1.99-x(1-x)\left(2.15-3.93 x+2.7 x^{2}\right)\right]}{(1+2 x)(1-x)^{3 / 2}}
\end{aligned}
$$

where $P_{\mathrm{Q}}$ is the maximum load from the load-displacement plot, $S$ is the support span, $f(x)$ accounts for the correction due to the specimen geometry. The fracture toughness results are summarized in Table 3 for Epon ${ }^{\circledR} 828$ and Epon ${ }^{\circledR} 826$ systems including their nanocomposites with different processing conditions. From Figure 10 it is seen that Epon ${ }^{\circledR}$ 828 nanocomposites with fiber loading of $0.3 \mathrm{wt} \%$ show a small increase in fracture toughness. The fracture toughness decreases in the nanocomposite with $2.0 \mathrm{wt} \%$ fiber loading is probably due to the increased agglomeration of nanofibers. A similar phenomenon was reported by Bakis and Temple-Boyer [26], who observed poor dispersion for higher concentrations of nanotubes. Generally, for various processing and fiber loading conditions, the fracture toughness in nanocomposite materials did not increase. In other similar fracture experiments of several different kinds of nanocomposite materials, no significant increase in fracture toughness was reported [20,27-30]. For example, inorganic $\mathrm{SiO}_{2}$ particulate fillers were used in polypropylene (PP) and PMMA to study the mechanical behavior of nanocomposites [31]. It is reported that at the high filler content, the nanocomposite toughness rapidly decreased due to agglomeration of the nanoparticles. Walter and Sholapurmath investigated the fracture toughness and mechanism in pure polystyrene and their nanocomposite materials, and concluded that the toughness was governed by crazing [27]. Pure polystyrene materials showed large craze zones and led to higher toughnesses while introduction of nanoscale reinforcements appeared to interrupt crazing and resulted in less tough materials.

\section{Effects of Nanofiber Waviness and Agglomeration on Composite Properties}

From previous experimental results, we found that the Young's moduli of nanocomposites did not increase as expected after we added very stiff nanofibers or

Table 3. Summary of fracture toughness data from SENB tests.

\begin{tabular}{llcc}
\hline $\begin{array}{l}\text { Epoxy/Composite } \\
\text { Group Code }\end{array}$ & \multicolumn{1}{c}{ Description } & $\begin{array}{c}\text { No. of } \\
\text { Specimens }\end{array}$ & \begin{tabular}{c} 
Toughness Data \\
\cline { 3 - 4 }
\end{tabular} \\
\hline F1E & Epon $^{\circledR} 828$ resin & 3 & $2.14 \pm 0.23$ \\
F16C & Epon $^{\circledR} 828$ resin, 0.3 wt\% fibers, no sonication & 2 & $2.35 \pm 0.31$ \\
F21C & Epon $^{\circledR} 828$ resin, 2.0 wt\% fibers, Low sonication & 4 & $1.38 \pm 0.64$ \\
F28E & Epon $^{\circledR} 826$ resin & 3 & $2.20 \pm 0.30$ \\
F29C & Epon $^{\circledR} 826$ resin, 0.3 wt\% fibers, Low sonication & 4 & $1.10 \pm 0.32$ \\
F30C & Epon $^{\circledR} 826$ resin, 5.0 wt\% fibers, Low sonication & 4 & $2.17 \pm 0.38$ \\
\hline
\end{tabular}




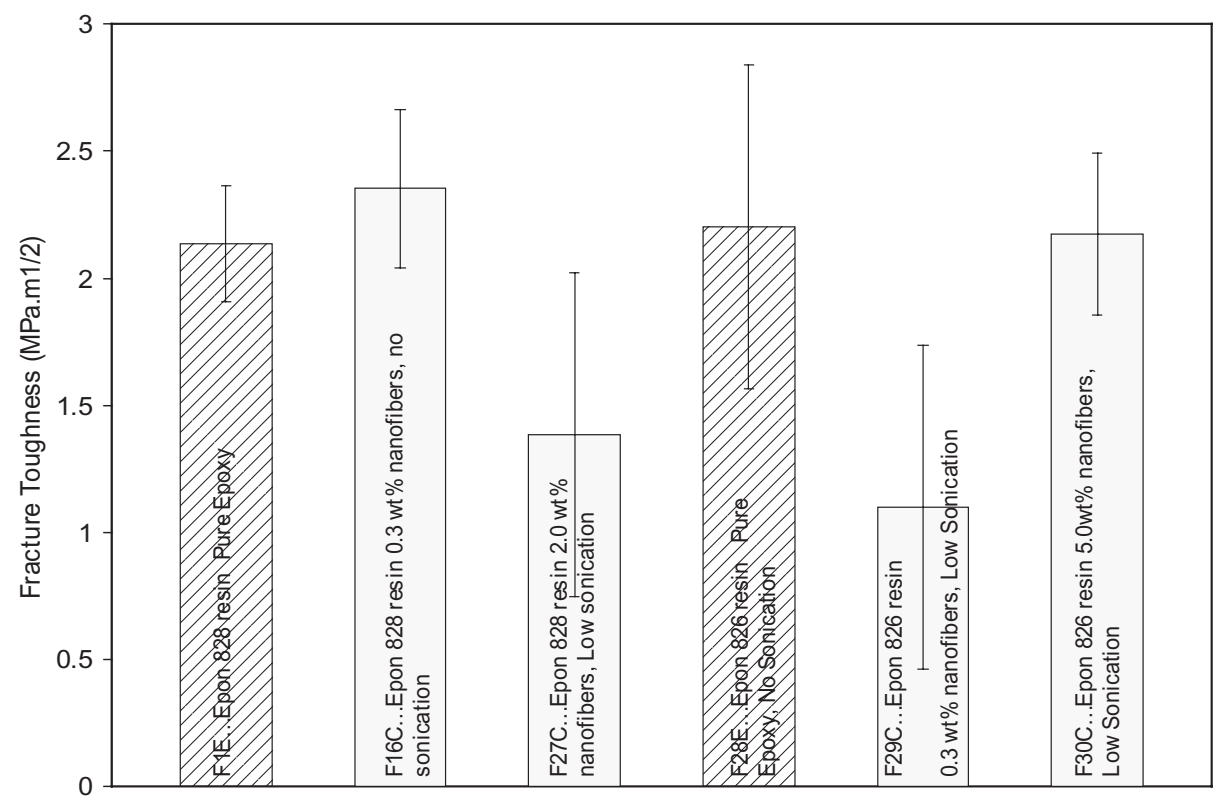

Figure 10. Fracture toughness comparison of two pure epoxy systems and their nanocomposites.

nanotubes. This kind of phenomenon needs an in-depth explanation from both mechanics and materials viewpoints. As seen in the TEM micrograph in Figure 2(b), there is some fiber waviness and agglomeration inside nanocomposites. Similar situations were extensively reported for all kinds of nanocomposites. These two factors definitely affect the stiffness and strength of nanocomposites. Recent experimental investigations have shown that increasing the aspect ratio did not improve the mechanical properties [32] since nanotubes/nanofibers tend to curl up and form bundles more easily due to their low bending stiffness and high aspect ratio $[33,34]$. As a result of agglomeration, some regions of nanocomposites have greater concentrations of nanotubes/nanofibers. Obviously, agglomeration has a significant effect on the strength and stiffness of nanocomposites.

A micromechanics-based model developed by Shi et al. predicted very high stiffness properties for carbon nanotubes composites [35]. Their initial study was based on the original Mori-Tanaka's model, which is quite simple and accurate for low volume fractions of reinforcements. However, comparison to experimental data showed a substantial discrepancy between the theoretical values and experimental data. Therefore, they attempted to model curviness and agglomeration of nanotubes and found that when all nanotubes have agglomerated, there was no evident stiffening effect of the addition of nanotubes. When partial agglomeration was considered, there was a rapid decrease in composite elastic moduli. Fisher et al. also concluded that the waviness significantly affected the composite stiffness using a multi-scale model [36].

\section{Failure Feature and Design Consideration of Nanocomposites}

In order to understand low strength and fracture toughness values of nanocomposite materials, general toughening mechanics should be analyzed first. Usually, material failure 
is governed by a main crack nucleating from defects inside the matrix or at the interface between the matrix and the reinforcement. Moreover, the crack propagation or arrest strongly depends on the degree of constraint offered by the reinforcement. This constraint is directly related to the effect of load transfer from the matrix to the reinforcement. Obviously, short fibers are not as effective as long continuous fibers in providing strong constraint to arrest a crack. As illustrated in Figure 11(a), failure in these nanocomposites tends to be matrix dominated especially for low volume or weight percents of reinforcements. Compared to long fiber-reinforced composites in Figure 11(b), the main crack will be constrained by these strong long fibers so the strength and toughness values along the fiber direction in these composites are much large than the values of the pure matrix. Actually, since applied load acting on the nanocomposite is mainly carried by the matrix and only partial load is transferred into nanoscale reinforcements through interfacial shear, it is not surprising that the strength and fracture toughness of nanocomposite materials do not increase significantly. This situation is quite similar to the transverse mechanical properties of long fiber composite materials. For long fiber composite materials, transverse mechanical properties are very close to that of the matrix since transverse mechanical properties are mainly governed by the matrix [37]. For most of current nanocomposites, they exhibited matrix-dominated failure feature, e.g., matrix cracking in composite materials [38]. Another special failure feature of nanocomposite materials is the agglomeration of nanofibers acting as initial defects. This is perhaps leading to a main crack initiation at those sites.

We also should pay great attention to the presence of stress singularity at the ends of nanofibers/nanotubes inside a matrix. It is well known that a high stress singularity/ concentration occurs at the locations where discontinuity either in material or geometry exists as shown in Figure 12 [39]. It was found that interfacial shear stress concentration is quite high when the moduli ratio of the fiber and the matrix $E_{\mathrm{f}} / E_{\mathrm{m}}$ is high [40]. These results based on previous traditional composites are still applicable to nanocomposites materials although the Young's moduli of nanofibers or nanotubes are much higher than the Young's moduli of any other traditional reinforcements. Therefore, the interfacial shear stress singularity/concentration of the nanocomposite should be much severe than that of traditional composites. In order to characterize the stress singularity/concentration at the interface between the matrix and reinforcements, we mainly use two Dunders'

(a)

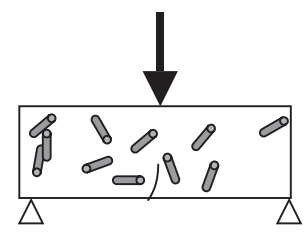

(b)

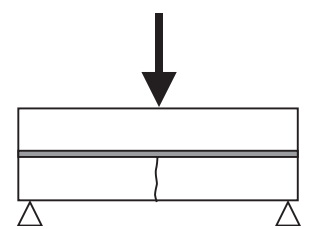

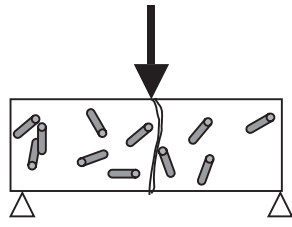

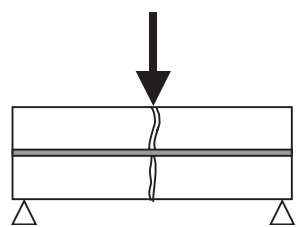

Figure 11. (a) Crack propagating process from a matrix in a short fiber composite, (b) crack propagating process from the matrix in a continuous fiber composite. 


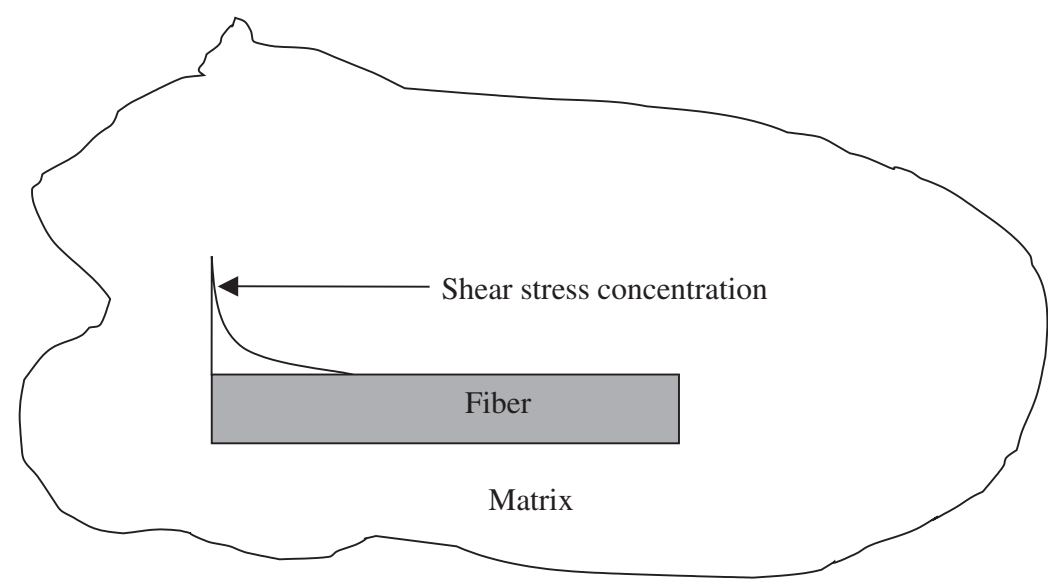

Figure 12. Illustration of the interfacial shear stress distribution for nanofiber composite materials.

parameters $(\alpha$ and $\beta$ ) to characterize the Young's modulus and bulk modulus mismatch of the fiber and the matrix [39]. Since no one has measured the bulk modulus for nanotubes or nanofibers so far, we only employ one Dunders' parameter to analyze our nanofiber composites under plane stress condition:

$$
\alpha=\frac{E_{\mathrm{f}}-E_{\mathrm{m}}}{E_{\mathrm{f}}+E_{\mathrm{m}}}
$$

We compare two composite systems with the same epoxy matrix (Young's modulus $E=2.6 \mathrm{GPa})$ reinforced by E-glass fibers $(E=72 \mathrm{GPa})$ and nanofibers $(E=600 \mathrm{GPa})$. Obviously, $\alpha_{\text {nanofiber/epoxy }}=0.99>\alpha_{\text {glass/epoxy }}=0.93$ and $\beta$, which can be calculated if we know the bulk modulus or Poisson's ratio of nanofiber/nanotubes, should be quite large too for nanofiber/nanotubes composites. Since these two material constants are related to property mismatch and interfacial stress, we can conclude that the interfacial stress level is quite high in nanocomposite materials. Higher interfacial stress will be directly related to the final failure strain of nanocomposites so it is probably the major reason contributing to the low failure strains in nanocomposites over their matrices.

After we investigate these special features of nanocomposite materials, we can provide some useful material design methodology for future nanocomposite developments. First, we should estimate the upper tensile strength limit of a nanocomposite. According to recent experimental investigations, the failure strain of nanocomposites is always less than that of the pure matrix. In order to get an increased strength, one should increase the stiffness of the nanocomposite. Here, we only employ the simple "rule of mixtures" to give an example. The upper bound of the longitudinal modulus for a composite can be expressed in terms of stiffness and volume fractions $V_{\mathrm{f}}$ and $V_{\mathrm{m}}$ of the fiber and the matrix as:

$$
E_{C}=E_{\mathrm{f}} v_{\mathrm{f}}+E_{\mathrm{m}} v_{\mathrm{m}}
$$

Therefore, we must increase the volume or weight percent of nanofibers to get higher composite stiffness since more applied load will be carried by stiff nanofibers or other 
nanoscale reinforcements. Also, the stiffness of a nanocomposite should be higher if the nanofibers/nanotubes are aligned [12]. There are a few studies on aligning nanofibers and nanotubes $[41,42]$ though their processes are not simple.

A simple shear-lag model [43] gives a more accurate expression for the stiffness for aligned short fiber composites as

$$
\begin{gathered}
E_{C}=E_{\mathrm{f}}\left[1-\frac{\tanh (\beta L / 2)}{\beta L / 2}\right] v_{\mathrm{f}}+E_{\mathrm{m}} v_{\mathrm{m}} \\
\text { where } \beta^{2}=\frac{2 \pi G_{\mathrm{m}}}{A_{\mathrm{f}} E_{\mathrm{f}} \ln (D / d)}
\end{gathered}
$$

where $G_{\mathrm{m}}$ is the shear modulus of the matrix, $L$ is the length of the fiber, $D$ is the outside diameter of the Representative Volume Element (RVE) and $d$ is the diameter of the short fiber. This formula reduces to the rule of mixtures for large $L$. But we can see that the longitudinal modulus of the short fiber composites (small $L$ ) is always less than that of long fiber composites (large $L$ ). From this simple analysis, we introduce another important design consideration on the minimum length of the nanoscale reinforcement in nanocomposites. If all other properties and dimensions are the same, the length of the nanofiber or nanotubes will determine the mechanical properties of nanocomposites [14]. It is very important that a fiber needs to be longer than a certain length known as load transfer length. This is the smallest length for which the stress in the fiber reaches its maximum value for a given composite stress. This critical length $L_{\mathrm{c}}$ is mainly determined by the fiber tensile strength $S_{\mathrm{f}}$, the fiber diameter $d$, and the interfacial shear strength $\tau_{i}$ between the fiber and the matrix [43]

$$
L_{\mathrm{c}}=\frac{d s_{\mathrm{f}}}{2 \tau_{i}}
$$

So for strong interfacial bonding between the fiber and the matrix, the critical length should be smaller in order to prevent rupture of the fiber. The tensile strength of the nanofiber is around $3.6 \mathrm{GPa}$ (strength of VGCFs; see [44]) and its diameter $d$ ranges from $10-200 \mathrm{~nm}$. Although the intrinsic interfacial shear strength is hard to measure and it is also compounded with the free-edge stress singularity during fiber push-out or pull-out tests [45], we can use its upper bound, i.e., the matrix shear strength to estimate the average interfacial shear strength. If we take the shear strength of epoxy as $0.97 \mathrm{GPa}$ [46], then the minimum nanofiber length should be between $19-370 \mathrm{~nm}$ according to Equation (7). In this investigation, our nanofiber length is around 5-10 $\mu \mathrm{m}$. In reality, the actual interfacial shear strength is far below the matrix shear strength. For example, if we use the average interfacial shear strength of $37 \mathrm{MPa}$ for the same epoxy Epon 828 but E-glass fiber interface [46], the minimum nanofiber length should be $0.5-10 \mu \mathrm{m}$. From this simple analysis, we can see that the product of the tensile strength of nanoscale reinforcement and its diameter (or smallest dimension) is an important material design parameter. In summary, in order to design strong nanocomposite materials, one must use aligned nanofibers or nanotubes with a relatively large volume or weight fraction. Also, the length of the nanofibers or nanotubes should be long enough and the diameter of nanofibers or the nanotubes not very small since only the product of the diameter and the tensile 
strength is related to local load transfer (see Equation (7)). The advantage of small diameters of nanofibers or the nanotubes is the increasing interfacial area with the matrix, while its shortcoming is the high possibility to get initial interfacial defects which may induce main cracks. So the diameter of nanotubes/nanofibers should not be too small from a viewpoint of mechanics.

\section{CONCLUSIONS}

Systematic mechanical property characterizations including bending, tensile, and fracture properties for a new functionalized nanofiber/epoxy composite were conducted. Results show that there was only very little increase in mechanical properties of nanocomposites although we used GCNF-ODA reactive linkers to improve the interface. Strong interface is a necessary condition but not a sufficient condition to produce strong and tough nanocomposites. Low-power ultrasonication is helpful in dispersing nanofibers and improving mechanical properties while high-power sonication may damage the molecular structures. The interfacial stress level of nanocomposites should be much higher than that of traditional composites because of high property mismatch between the nanoscale reinforcements and the matrix. Since higher interfacial stress is directly related to the final failure of nanocomposites, it is probably the major reason contributing to the low failure strains in nanocomposites over their matrices. In order to design strong and stiff nanocomposite materials, one must use aligned nanofibers or nanotubes with a relatively large volume or weight fraction. Also, the length of the nanofiber or nanotubes should be quite long and the diameter of nanofibers or the nanotubes not very small. The advantage of small diameters of nanofibers or the nanotubes is the increasing interfacial area with the matrix while its shortcoming is the high possibility of getting initial interfacial defects.

\section{ACKNOWLEDGMENTS}

CML and LRX gratefully acknowledge the support of Vanderbilt University through an Interdisciplinary Discovery Grant. LRX gratefully acknowledges the support of the U.S. Office of Naval Research through an ONR Young Investigator Award (\#N00014-031-0505). VB acknowledges a Nano-fellowship support from the Vanderbilt Institute of Nanoscale Science and Engineering. Part of the research conducted at the Oak Ridge National Laboratory was sponsored by the Assistant Secretary for Energy Efficiency and Renewable Energy, Office of Transportation Technology, as part of the High Temperature Materials Laboratory User Program, Oak Ridge National Laboratories, managed by UT-Battelle, LLC for the U.S. Department of Energy under contract number DE-AC05-00OR22725.

\section{REFERENCES}

1. Treacy, M.M.J., Ebbesen, T.W. and Gibson, T.M. (1996). Exceptionally High Young's Modulus Observed for Individual Carbon Nanotubes, Nature, 381(6584): 678-680.

2. Lau, K.T. and Hui, D. (2002). The Revolutionary Creation of New Advanced Materials - Carbon Nanotubes Composites, Composites, Part B, 33(4): 263-277. 
3. Qian, D., Wagner, G.J. and Liu, W.K., Yu Min-Feng, Ruoff, R.S. (2002). Mechanics of Carbon Nanotubes, Appl. Mech. Rev., 55(6): 495-533.

4. Luo, J.J. and Daniel, I.M. (2003). Characterization and modeling of mechanical behavior of polymer/clay nanocomposites, Composites Science and Technology, 63(11): 1607-1616.

5. Wagner, H.D., Lourie, O., Feldman, Y. and Tenne, R. (1998). Stress-induced Fragmentation of Multiwall Carbon Nanotubes in a Polymer Matrix, Applied Physics Letters, 72(2): 188-190.

6. Qian, D., Dickey, E.C., Andrews, R. and Rantell, T. (2000). Load Transfer and Deformation Mechanisms in Carbon Nanotube-Polystyrene Composites, Appl. Phys. Lett., 76(20): 2868-2870.

7. Yu, M.F., Lourie, O., Dyer, M., Moloni, K. and Kelly, T., Ruoff, R.S. (2000). Strength and Breaking Mechanism of Multi-walled Carbon Nanotubes Under Tensile Load, Science, 287(5453): 637-640.

8. Kim, J.Y., Yu, L. and Hahn, T. (2003). Graphite Nanoplatelet/Epoxy Vinyl Ester Composites, Proceedings of the International Conference on Composite Materials (ICCM) - 14 .

9. Schadler, L.S., Giannaris, S.C. and Ajayan, P.M. (1998). Load Transfer in Carbon Nanotube Epoxy Composites, Appl. Phys. Lett., 73(26): 3842-3844.

10. Zerda, A.S. and Lesser, A.J. (2001). Intercalated Clay Nanocomposites: Morphology, Mechanics, and Fracture Behavior, Journal of Polymer Science Part B: Polymer Physics, 39(11): 1137-1146.

11. Bucknall, C.B., Karpodinis, A. and Zhang, X.C. (1994). A Model for Particle Cavitation in Rubber-toughened Plastics, Journal of Materials Science, 29(13): 3377-3383.

12. Odegard, G.M., Gates, T.S., Wise, K.E., Park, C., Siochi E.J. (2003). Constitutive Modeling of Nanotube-reinforced Polymer Composites, Composites Science and Technology, 63: 1671-1687.

13. Ajayan, P.M., Schadler, L.S., Giannaris, C. and Rubio, A. (2000). Single-walled NanotubePolymer Composites: Strength and Weaknesses, Advanced Materials, 12(10): 750-753.

14. Frankland, S.J.V., Harik, V.M., Odegard, G.M., Brenner, D.W. and Gates, T.S. (2003). The Stress-Strain Behavior of Polymer-Nanotube Composites from Molecular Dynamics Simulation, Composites Science and Technology, 63: 1655-1661.

15. Thostenson, E.T., Zhifeng, R. and Chou-Tsu, W. (2001). Advances in the Science and Technology of Carbon Nanotubes and their Composites: a Review, Composites Science and Technology, 61(13): 1899-1912.

16. Andrews, R., Jacques, D., Minot M. and Rantell, T. (2002). Fabrication of Carbon Multiwall Nanotube/Polymer Composites by Shear Mixing, Macromolecular Materials and Engineering, 287(6): 395-403.

17. Wetzel, B., Haupert, F., Friedrich, K., Zhang, M.Q. and Rong, M.Z. (2002). Impact and Wear Resistance of Polymer Nanocomposites at Low Filler Content, Polymer Engineering and Science, 42(9): 1919-1927.

18. Xu, L.R. and Rosakis, A.J. (2002). Impact Failure Characteristics in Sandwich Structures; Part II: Effects of Impact Speed and Interfacial Strength, International Journal of Solids and Structures, 39: 4237-4248.

19. Xu, L.R., Huang, Y.Y. and Rosakis, A.J. (2003). Dynamic Crack Deflection and Penetration at Interfaces in Homogeneous Materials: Experimental Studies and Model Predictions, Journal of the Mechanics and Physics of Solids, 51: 425-460.

20. Lau, K.T., Shi, S.Q., Zhou, L.M. and Cheng, H.M. (2003). Micro-hardness and Flexural Properties of Randomly-oriented Carbon Nanotube Composites, Journal of Composite Materials, 37(4): 365-376.

21. Park, S.S., Bernet, N., De La Roche, S. and Hahn, H.T. (2003). Processing of iron oxide-epoxy vinyl ester nanocomposites, Journal of Composite Materials, 37(5): 465.

22. Paxton, J.P., Mowles, E.D., Lukehart, C.M. and Witzig, A.J. (2001). In: Hyer, M.W. and Loos, A.C. (Eds), Proceedings of the American Society for Composites 16th Technical Conf., Sept. 9-12, pp. 215-221, Blacksburg, Virginia.

23. Zhong, W.H., Li, J., Xu, L.R., Michel, J.A., Sullivan, L.M. and Lukehart, C.M. (2004). Processing of Polymeric Nanocomposites Reinforced with Derivatized Graphitic Carbon Nanofibers with Linker Molecules. Journal of Nanoscience and Nanotechnology, in press. 
24. Srivastava, D., Wei, C. and Cho, K. (2003). Nanomechanics of Carbon Nanotubes and Composites, ASME Appl. Mech. Rev., 56(2): 215-230.

25. Sandler, J., Werner, P., Shaffer, M.S.P., Demchuk, V., Altstadt, V. and Windle, A.H., (2002). Carbon-nanofibre-reinforced poly(ether ether ketone) Composites, Composites- Part A: Appl. Sci. \& Manufac., 33(8): 1033-1039.

26. Bakis, C.E. and Temple-Boyer, C.F. (2003). Tensile Creep Behavior of Carbon Nanotube Reinforced Epoxy, Proceedings of the International Conference on Composite Materials $(I C C M)-14$.

27. Walter, M.E. and Prashant, S. (2002). Fracture of Polystyrene/Clay and Polystyrene/ Nanoporous Silica Nanocomposites, Proceedings of Society of Experimental Mechanics (SEM) Conference.

28. Singh, R.P., Vasil, T. and Mei, Z. (2002). Processing and Characterization of PolyesterAluminum and Polyester-Alumina Nanocomposites, Proceedings of Society of Experimental Mechanics (SEM) Conference.

29. Zhan, G.D., Kuntz, J.D., Wan, J. and Mukherjee, A.K. (2002). Alumina-based Nanocomposites Consolidated by Spark Plasma Sintering, Scripta Materialia, 47(11): 737-741.

30. Roy, S., Lu, H., Periasamy, S. and Ma, J. (2003). Characterization and Modeling of the Fracture Behavior of Epoxy Nanocomposites, Proceedings of the 44th AIAA/ASME/ASCE/AHS Structures, Structural Dynamics, and Materials Conference, Norfolk, Virginia.

31. Rong, M.Z., Zhang, M.Q., Zheng, Y.X., Zeng, H.M., Walter, R. and Friedrich, K. (2001). Structure-Property Relationships of Irradiation Grafted Nano-inorganic Particle Filled Polypropylene Composites, Polymer, 42(7): 167-183.

32. Bai, J.B. and Allaoui, A. (2003). Effect of the Length and the Aggregate Size of MWNTs on the Improvement Efficiency of the Mechanical and Electrical Properties of Nanocomposites, Composites, Part A, 34(2003): 689-694.

33. Shaffer, M.S. and Windle, A.H. (1999). Fabrication and Characterization of Carbon Nanotube/ Poly(vinyl alcohol) Composites, Adv. Mater., 11(11): 937-941.

34. Vigolo, B., Penicaud, A.P., Couloun, C., Sauder, S., Pailler, R., Journet, C., Bernier, P. and Poulin, P. (2000). Microscopic Fibers and Ribbons of Carbon Nanotubes, Science, 290(5495): $1331-1334$.

35. Shi, D.L., Xi-Qiao, F., Yongang, Y.H. and Keh-Chih, H. (2003). The Effect of Nanotube Waviness and Agglomeration on the Elastic Property of Carbon Nanotube-reinforced Composites, Submitted to Journal of Mechanics and Physics of Solids.

36. Fisher, F.T., Bradshaw, R.D., Brinson, L.C. (2003). Fiber Waviness in Nanotube-reinforced Polymer Composites: I. Modulus Predictions Using Effective Nanotube Properties, Composites Science and Technology, 63(11): 1689-1703.

37. Jones, R.M. (1999). Mechanics of Composite Materials, 2nd Edn, Taylor and Francis Inc, Pennsylvania.

38. Xu, L. (1995). Influence of Stacking Sequence on the Transverse Matrix Cracking in Continuous Fiber Crossply Laminates, Journal of Composite Materials, 29(10): 1337-1339.

39. Bogy, D.B. (1971). Two Edge-bonded Elastic Wedges of Different Materials and Wedge Angles Under Surface Traction, Journal of Applied Mechanics, 38: 377-386.

40. Sun, C.T. and Wu, J.K. (1983). Stress Distribution of Aligned Short-fiber Composites Under Axial Load, Journal of Reinforced Plastics and Composites, 3(2): 130-144.

41. Jin, L., Bower, C. and Zhou, O. (1998). Alignment of Carbon Nanotubes in a Polymer Matrix by Mechanical Stretching, Appl. Phys. Lett., 73(9): 1197-1199.

42. Haggenmueller, R., Gommans, H.H., Rinzler, A.G., Fischer, Je.E. and Winey, K.I. (2000). Aligned Single-wall Carbon Nanotubes in Composites by Melt Processing Methods, Chem. Phys. Lett., 330(3-4): 219-225.

43. Gibson, R.F. (1994). Principles of Composite Material Mechanics, McGraw-Hill, Inc., New York.

44. Hashishin, T., Iwanaga, H., Ichihara, M. and Mukai, S.R. (2003). Core Structure of Vapor Grown Carbon Fibers and Morphology Dependence of Tensile Strength, Carbon, 41 (2003): 343-349. 
45. Xu, L.R., Kuai, H. and Sengupta, S. (2004). Free-edge Stress Singularities and Edge Modifications for Fiber Pushout Experiments, Submitted for publication.

46. Liu, Chun-Hsin and Nairn, J.A. (1999). Analytical and Experimental Methods for a Fracture Mechanics Interpretation of the Microbond Test Including the Effects of Friction and Thermal Stresses, International Journal of Adhesion \& Adhesives, 19: 59-70. 